\title{
Numerical study of barite precipitation in porous media under deep geothermal conditions
}

\author{
FLORIAN CAZENAVE ${ }^{1}$, PIERRE BACHAUD ${ }^{2}$, LIDIA CASAS ${ }^{1}$, \\ PIERRE CEZAC ${ }^{1}$, HANNELORE DERLUYN ${ }^{3}$, AUDREY \\ ESTUBLIER $^{2}$, CLEMENTINE MEILLER $^{2}$ \\ ${ }^{1}$ Université de Pau et des Pays de l'Adour, E2S UPPA, \\ Laboratoire de Thermique, Energétique et Procédés, Pau, \\ France, fl.cazenave@univ-pau.fr \\ ${ }^{2}$ IFP Energies nouvelles, Rueil-Malmaison, France \\ ${ }^{3}$ Université de Pau et des Pays de l'Adour, E2S UPPA, \\ CNRS, Total, Laboratoire des Fluides Complexes et leurs \\ Réservoirs, Pau, France
}

With the growing energy needs of our contemporary society, new sources of energy and technologies must be developed. Geothermal energy is a renewable resource that has the advantage, among others, of being continuously available. One of the main barriers to its development is its high cost, partly attributable to the occurrence of fouling in both the surface equipment and the injection well. Indeed, this phenomenon drastically reduces the injectivity of the well and the long-term efficiency of the power plant, and maintenance operations are required.

In order to mitigate efficiently the deposits, the prediction of barite precipitation -one of the main components of the scales- needs to be improved in deep geothermal conditions, in particular by introducing a rigorous nucleation model and expanding the experimental data for cristallisation models available in the literature to higher temperatures. This is the framework of the DEEPCHEM project, conducted in collaboration between the Laboratoire de Thermique, Energétique et Procédés (LaTEP) and IFP Energies nouvelles (IFPEN), and supported by CARNOT ISIFoR and IFPEN.

In that prospect, the proposed approach is based on reactive transport modeling. Existing thermokinetic models describing both the nucleation and the growth phase of barite precipitation, are revised and complemented. Indeed, missing literature data such as metastability limit for the nucleation and growth kinetic parameters at high temperature (up to $200^{\circ} \mathrm{C}$ ) are determined from laboratory experiments. These models are implemented in CooresFlow, a reactive transport calculation code developed by IFPEN. After model validation by comparison with experimental data, simulations are conducted under typical geothermal conditions considering a water composition from the Rhine Graben in France to assess barite formation in an injection well. 